Supporting Information

\title{
Flexible sulfide electrolyte thin membrane with ultrahigh ionic conductivity for all-solid-state lithium batteries
}

Zhihua Zhang ${ }^{a \neq}$, Liping Wu ${ }^{a, b \neq}$, Dong Zhou ${ }^{a \neq}$, Wei Weng ${ }^{a, b}$, Xiayin Yao ${ }^{a, b *}$

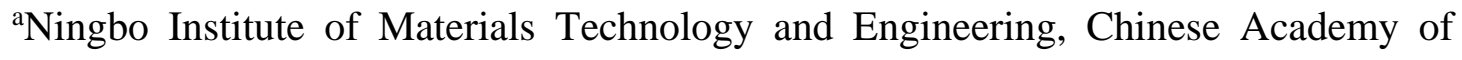

Sciences, Ningbo 315201, P.R. China

${ }^{\mathrm{b}}$ Center of Materials Science and Optoelectronics Engineering, University of Chinese Academy of Sciences, Beijing 100049, P. R. China

Corresponding Author: Xiayin Yao*, Email: yaoxy@nimte.ac.cn.

\$Zhihua Zhang, Liping Wu, and Dong Zhou contributed equally to this work. 


\section{Experimental Section}

\section{Materials}

The reagent-grade PTFE fine powder $\left(M_{\mathrm{w}}\right.$ of $\left.10^{6} \sim 10^{7}\right), \mathrm{Li} 2 \mathrm{~S}(99.98 \%), \mathrm{P}_{2} \mathrm{~S}_{5}(99 \%)$, and $\mathrm{LiCl}$ (99.0\%) were purchased from Sigma-Aldrich without further purification. $\mathrm{LiNi}_{0.5} \mathrm{Co}{ }_{0.2} \mathrm{Mn}_{0.3} \mathrm{O}_{2}(\mathrm{NCM})$ cathode powder was obtained from commercial sources, and its XRD and SEM are shown in Figure S10 and Figure S11, respectively. Li foils with a thickness of $80 \mu \mathrm{m}$ were purchased from China Energy Lithium Co., Ltd. All preparation processes were carried out in an argon-filled glove box with $\mathrm{H}_{2} \mathrm{O}<0.1 \mathrm{ppm}$ and $\mathrm{O}_{2}<0.1 \mathrm{ppm}$ (Lab Star, Mbraun, Germany) due to the oxygen and moisture sensitive of the raw materials.

\section{Preparation of $\mathrm{Li}_{5.4} \mathrm{PS}_{4.4} \mathrm{Cl}_{1.6}$ sulfide electrolyte}

$\mathrm{Li}_{2} \mathrm{~S}, \mathrm{P}_{2} \mathrm{~S}_{5}$, and $\mathrm{LiCl}$ were used as starting materials. Stoichiometric reagents based on $\mathrm{Li}_{7-x} \mathrm{PS}_{6-x} \mathrm{Cl}_{x}(x=1.4,1.5,1.6,1.7)$ were ball-milled for $15 \mathrm{~h}$ at $500 \mathrm{rpm}$ with a planetary ball mill apparatus. The obtained electrolyte precursor was sealed in quartz tube and annealed under various annealing conditions to obtain the final electrolyte. Li5.4 $\mathrm{PS}_{4.4} \mathrm{Cl}_{1.6}$ annealed at $510{ }^{\circ} \mathrm{C}$ for $2 \mathrm{~h}$ exhibit the highest ionic conductivity, which was chosen as the solid electrolyte (SE) powder for all-solid-state batteries (ASSLBs) in this work.

\section{Fabrication of SE membrane}

A certain amount Li5.4PS4.4Cl1.6, (99.8 wt.\%) and PTFE (0.2 wt.\%) powder was sealed in a $\mathrm{ZrO}_{2}$ jar and ball milled with a speed of $200 \mathrm{rpm}$ for $5 \mathrm{~min}$ to ensure the homogeneity of the obtained raw mixture and fibrillation of PTFE. The weight ratio of ball to material was 5:1, and the planetary ball mill setup is PM200, RETSCH. Then, a freestanding, continuous SE membrane was obtained by pressing the mixed powders together through the gap between two clean rolls of a hot calendering machine at $80{ }^{\circ} \mathrm{C}$ (MTI corporation). 


\section{Preparation of the $\mathrm{Al}_{2} \mathrm{O}_{3}$ coating layer}

Scrape the Li foil until the shiny surface appears. The pretreated Li foils were coated with a thin layer $\mathrm{Al}_{2} \mathrm{O}_{3}$ by radio frequency magnetron sputtering (RH450, SKY Technology Development Co., Ltd, CAS) with a commercial $\mathrm{Al}_{2} \mathrm{O}_{3} \operatorname{target}(99.99 \%)$ in the argon atmosphere at room temperature. The power was set to $90 \mathrm{~W}$ under $0.5 \mathrm{~Pa}$ argon pressure with a fixed target-to-substrate distance of $8 \mathrm{~cm}$. Before sputtering to the sample, the target was pre-sputtered for $15 \mathrm{~min}$ to remove contaminants on the surface. The substrate was rotated at a rate of $20 \mathrm{r} / \mathrm{min}$ to guarantee a uniform deposition and the sputtering speed is determined to be about $1.3 \mathrm{~nm} / \mathrm{min}$. The sputtering time was $5 \mathrm{~h}$.

\section{Materials characterization}

The height profile and surface roughness of SE membrane were investigated by an atomic force microscopy (AFM, Bruker Corporation). X-ray diffraction (XRD) measurements were used to characterize the surface structure of SEs on a Bruker AXS D8 Advance diffractometer with $\mathrm{Cu} K \alpha$ radiation. The Raman spectra were recorded by a laser beam at a wavelength of $532 \mathrm{~nm}$ from an argon ion laser of Raman spectrometer (Renishaw inVia Reflex). The morphology and elemental distribution were analyzed by a FEI Quanta FEG 250 field emission scanning electron microscopy (SEM) equipment with electron back scattered diffraction (EBSD) and energy dispersive X-ray spectroscopy (EDX). The valence state variation of elements was identified by X-ray photoelectron spectroscopy (XPS, AXIS ULTRA DLD).

\section{Cell assembly}

ASSLBs were assembled by isostatic cold pressing method. Specifically, a cathode layer $(\varphi 8 \mathrm{~mm})$ was firstly pressed onto a steel substrate under $200 \mathrm{MPa}$. Then cover it with the SE membrane $(\varphi 14 \mathrm{~mm})$ followed by another isostatic cold pressing under 500 $\mathrm{MPa}$. Finally, an $80 \mu \mathrm{m}$ thick $\mathrm{Li}$ foil $(\varphi 10 \mathrm{~mm})$ coated with $\mathrm{Al}_{2} \mathrm{O}_{3}$ was pressed on it. The electrodes were elicited by lugs, and the whole ASSLB was encapsulated in the Al 
plastic film. The cathode layer is a mixture of $\mathrm{Li}{ }_{5.4} \mathrm{PS}_{4.4} \mathrm{Cl}_{1.6}, \mathrm{NCM}$ powder, $\mathrm{VGCF}$, and PTFE in weight ratio of 30:70:2:1. Symmetric Li/Li cells are assembled as follow steps: firstly, the SE membrane was put into a nylon tube of $10 \mathrm{~mm}$ in diameter and press it under $360 \mathrm{MPa}$ to get a densified flake. Then, $\mathrm{Li}$ foils or $\mathrm{Li}$ foils with $\mathrm{Al}_{2} \mathrm{O}_{3}$ coating were attached on both sides of the SE flake and then pressed under $30 \mathrm{MPa}$. No extra stacking pressure was used during cell cycling.

\section{Electrochemical measurements}

Ionic conductivities $(\sigma)$ of the electrolytes were obtained from the equation: $\sigma=L / R S$, where $L$ represents the thickness, $S$ represents the effective contacting area between SE and blocking electrode, and $R$ represents the resistance. The $R$ of electrolytes were got via electrochemical impedance spectroscopy (EIS) test using a Solartron 1470E potentiostat electrochemical workstation in the frequency range of $10^{6} \mathrm{~Hz}-10^{-2} \mathrm{~Hz}$ with an amplitude of $10 \mathrm{mV}$. Carbon coated Al foils were chosen as the blocking electrodes and attached on both sides of the SE pellets. For the electrolyte powder, in order to minimize the error caused by the thickness measurement, about $250 \mathrm{mg} \mathrm{SE}$ powder was weighted and pressed in a nylon tube with diameter of $10 \mathrm{~mm}$ to get a densified pellet under $360 \mathrm{MPa}$. For the electrolyte membrane, carbon coated Al foils (blocking electrodes) were pressed on both sides of the SE membranes by isostatic cold pressing under $500 \mathrm{MPa}$ for $10 \mathrm{~min}$. During the conductivities test, all the samples were pressurized under $360 \mathrm{MPa}$, and the diameter of the blocking electrodes is $10 \mathrm{~mm}$. For the conductivity calculation of SE membrane, the disturbances from testing wires and electrical contact was emendated due to the very small absolute value for the thin membrane impedance value. The final impedance values for conductivity calculation are obtained by the tested impedance values subtracting the resistance contribution (1.04 $\Omega$, Figure S4b) from testing wires, electrical contact, etc. Moreover, to further verify the accuracy of the conductivity test for the thin SE membrane, a $1.65 \mathrm{~mm}$ pellet consisting of the membrane materials (PTFE and $\mathrm{Li}_{5.4} \mathrm{PS}_{4.4} \mathrm{Cl}_{1.6}$ ) was also tested (Figure $\mathrm{S} 4 \mathrm{c})$. Noting that for the conductivity calculation, only the EIS test values of the 
membrane sample subtracted the resistance contribution from testing wires, electrical contact, etc. The electronic conductivities of electrolytes were measured by applying a $0.5 \mathrm{~V}$ direct current voltage on the blocking electrode/electrolyte/blocking electrode cells. Galvanostatic charge-discharge cycling of ASSLBs and symmetric Li/Li cells were carried out on a standard battery test instrument (Wuhan Rambo Electronics Co., Ltd.) at $60{ }^{\circ} \mathrm{C}$. 
a
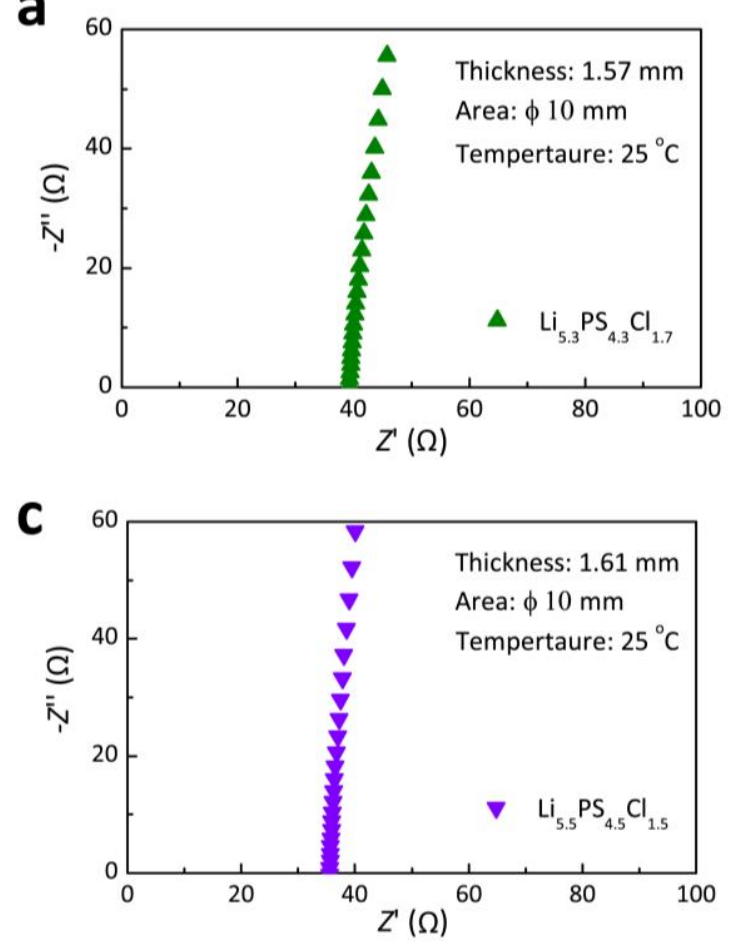

b
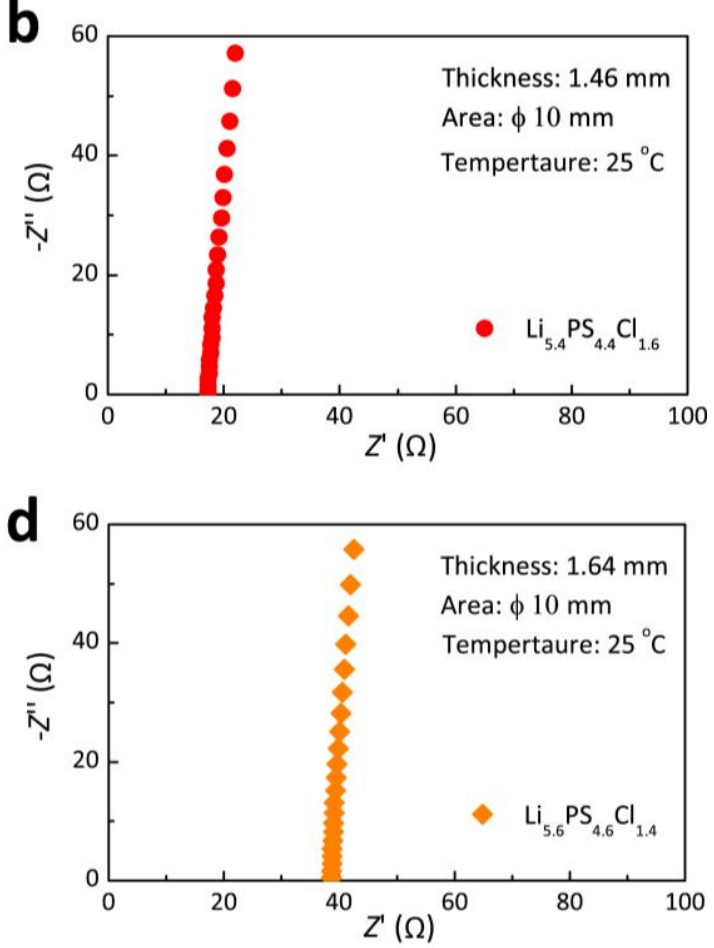

Figure S1. Nyquist plots of $\mathrm{Li}_{7-x} \mathrm{PS}_{6-x} \mathrm{Cl}_{x}(x=1.4,1.5,1.6,1.7)$ at $25^{\circ} \mathrm{C}$. 


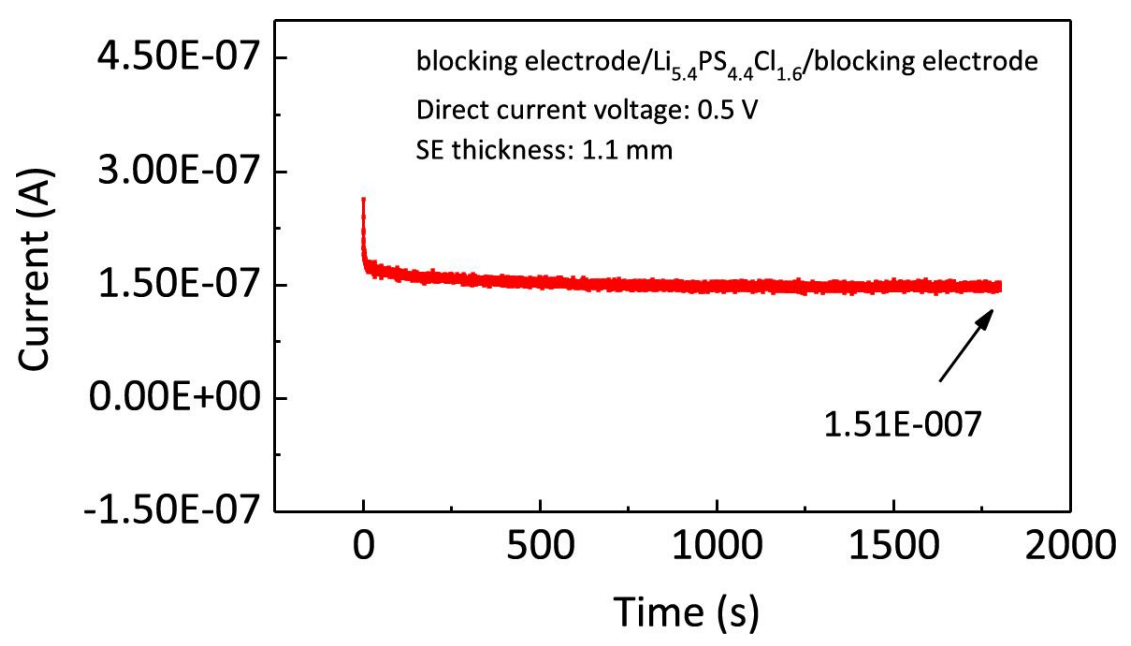

Figure S2. Electronic conductivity test for $\mathrm{Li}_{5.4} \mathrm{PS}_{4.4} \mathrm{Cl}_{1.6}$ at $25{ }^{\circ} \mathrm{C}$. 
a

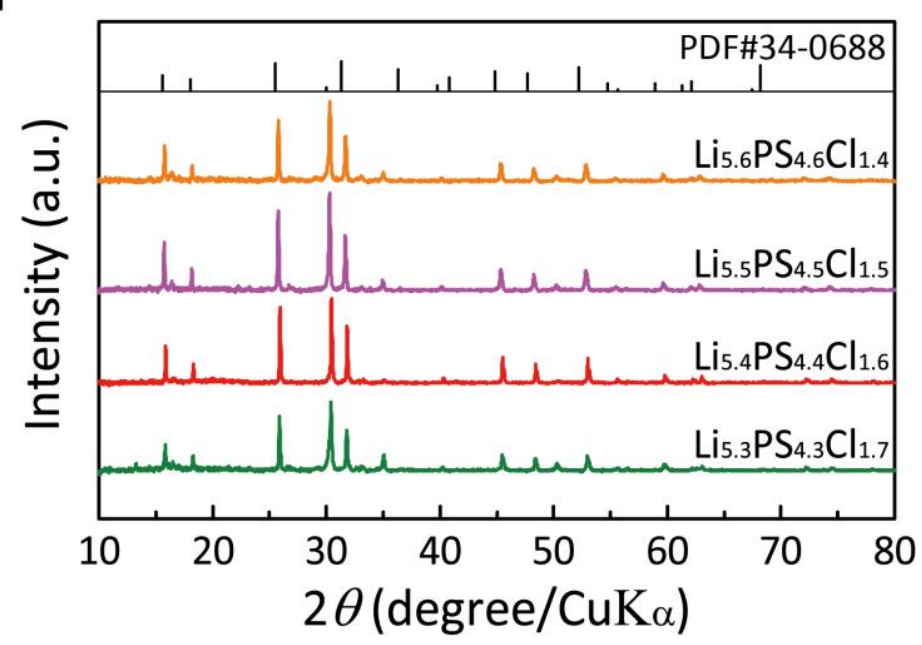

b

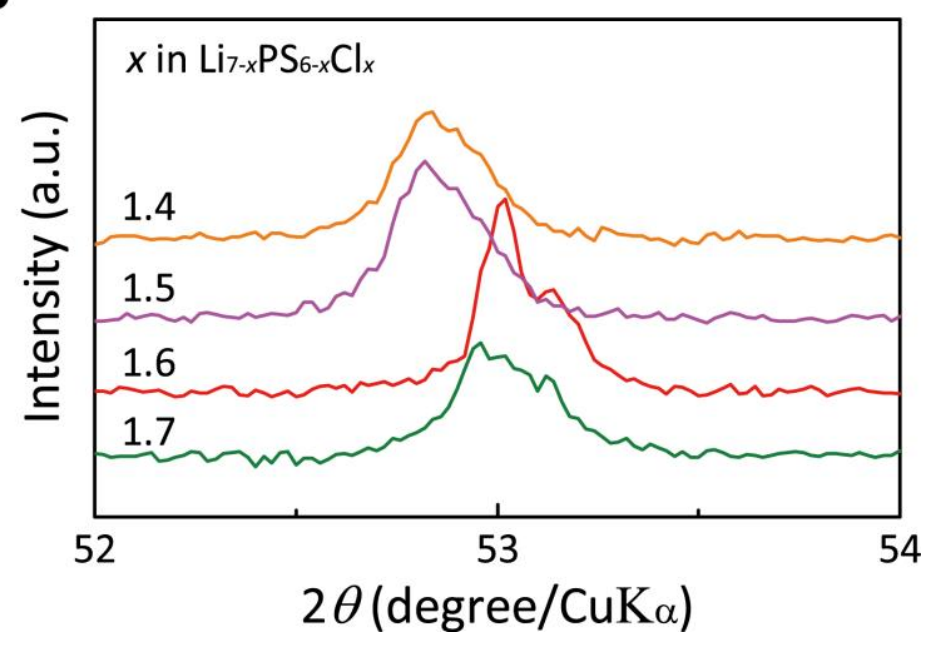

Figure S3. (a) XRD patterns and of $\mathrm{Li}_{7-x} \mathrm{PS}_{6-x} \mathrm{Cl}_{x}$. (b) Changes in Bragg diffraction peaks at 52 to 54 as a function of $x$ in $\mathrm{Li}_{7-x} \mathrm{PS}_{6-x} \mathrm{Cl}_{x}(x=1.4,1.5,1.6,1.7)$. 

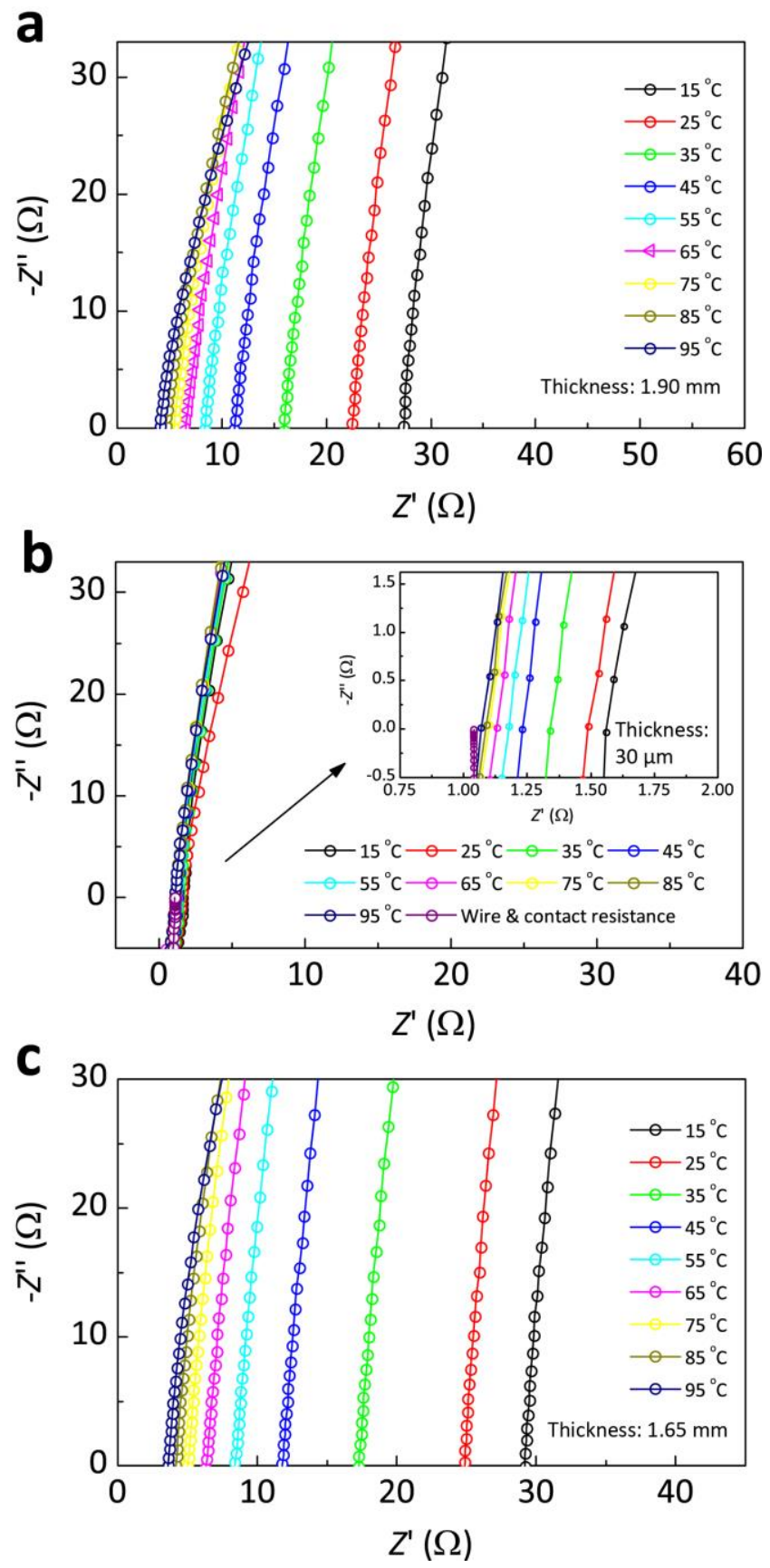

Figure S4. (a) Variable-temperature Nyquist plots of $\mathrm{Li}_{5.4} \mathrm{PS}_{4.4} \mathrm{Cl}_{1.6}$ powder with thickness of $1.9 \mathrm{~mm}$. (b) Variable-temperature Nyquist plots of the $30 \mu \mathrm{m}$ membrane. The impedance values for conductivity calculation are obtained by the tested impedance values subtracting the resistance contribution (1.04 $\Omega$ ) from testing wires, electrical contact, etc. (c) Variable-temperature Nyquist plots of a $1.65 \mathrm{~mm}$ pellet consists of the membrane materials (PTFE and $\mathrm{Li}_{5.4} \mathrm{PS}_{4.4} \mathrm{Cl}_{1.6}$ ). 


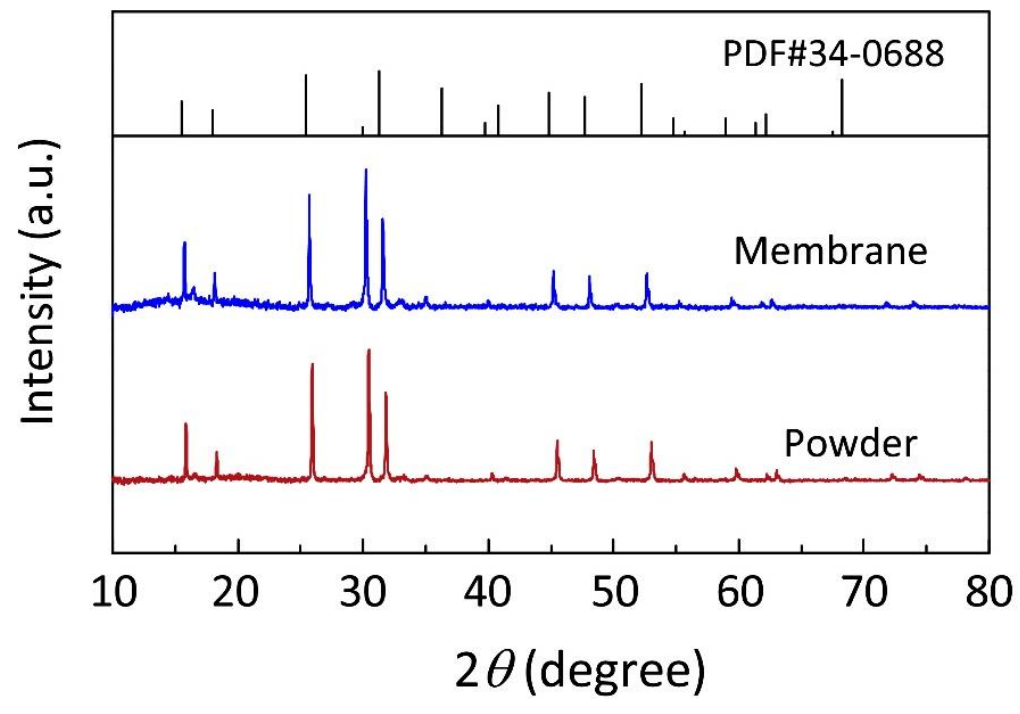

Figure $\mathrm{S} 5$. XRD patterns of the $\mathrm{Li}_{5.4} \mathrm{PS}_{4.4} \mathrm{Cl}_{1.6}$ powder and membrane. 


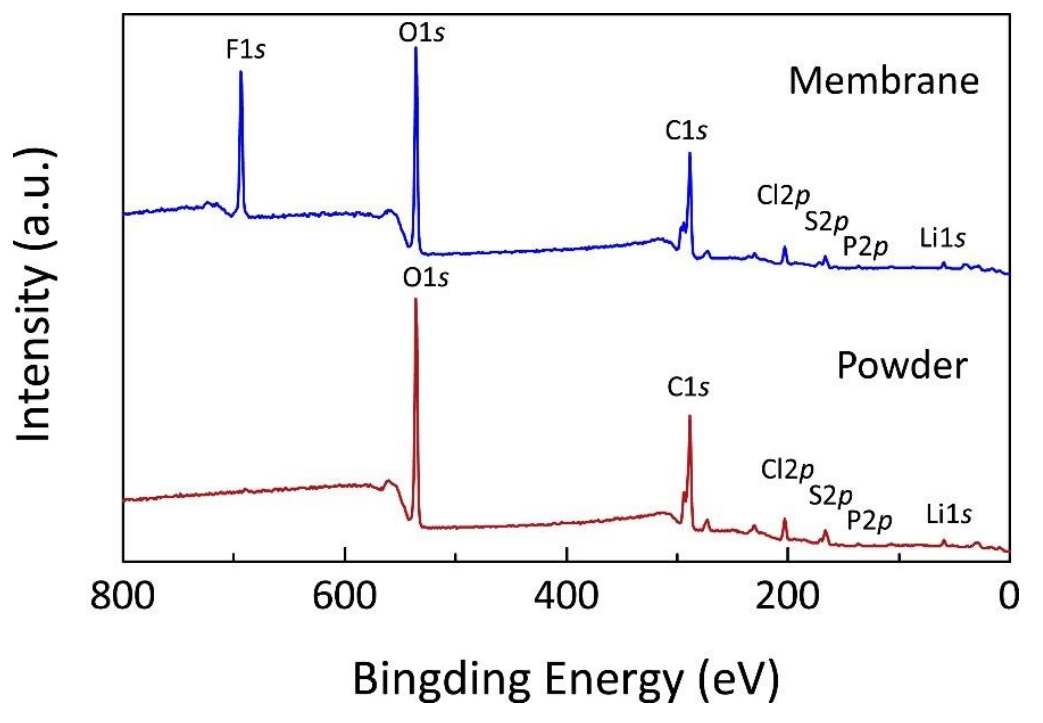

Figure S6. XPS spectra of SE powder and membrane. 

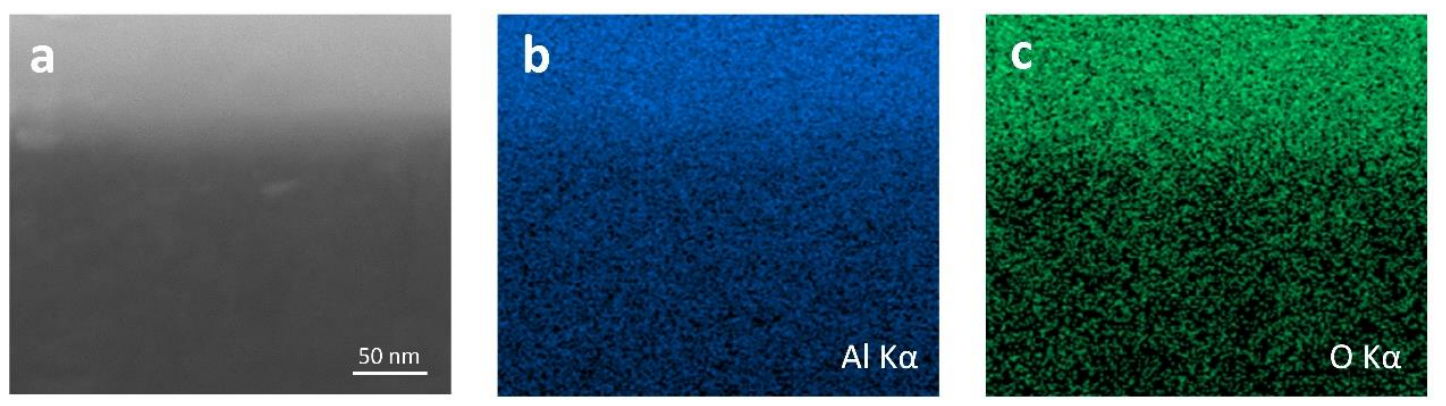

Figure S7. a) EBSD image and b-c) EDX element mapping of the $\mathrm{Li} / \mathrm{Al}_{2} \mathrm{O}_{3}$ interface. The dark areas on the figure corresponds to $\mathrm{Li}$, and the light one corresponds to $\mathrm{Al}_{2} \mathrm{O}_{3}$. 


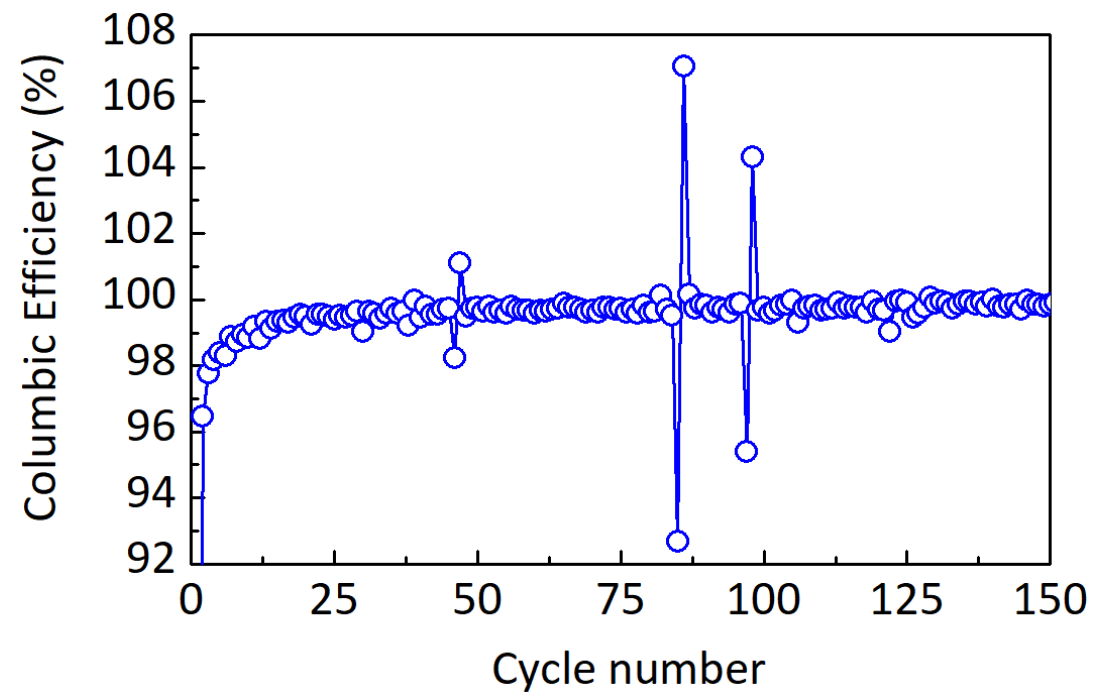

Figure S8. The enlarged Y-axis in Figure 4f to show Columbic efficiency from 92 to $108 \%$. 


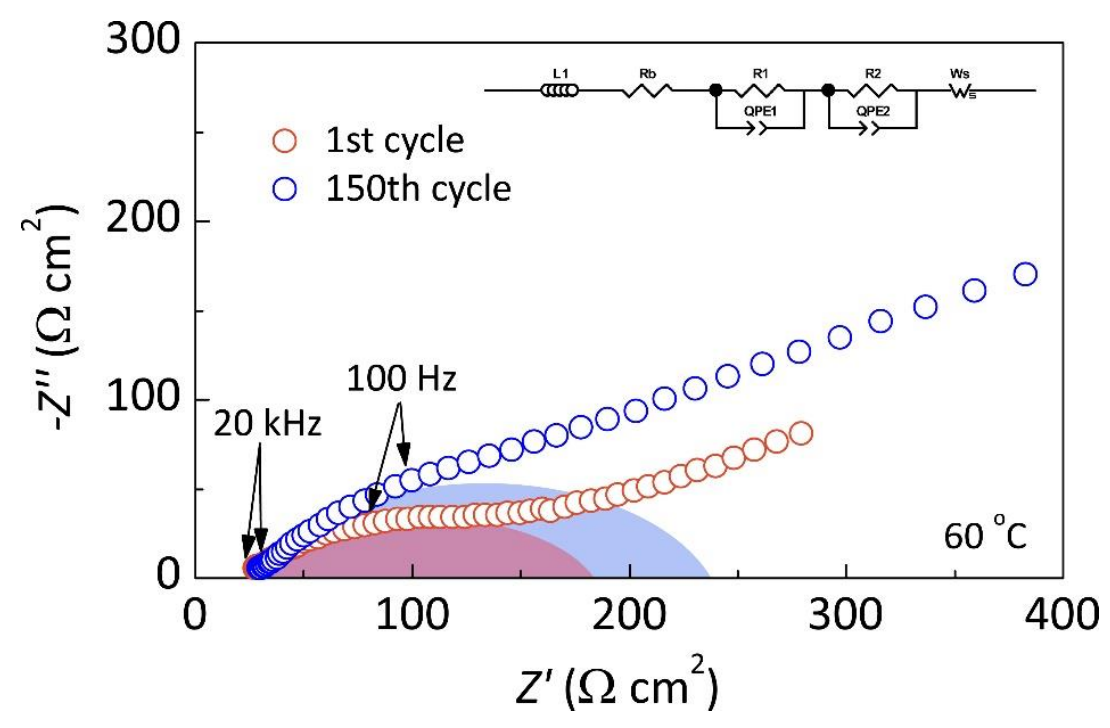

Figure S9. EIS Nyquist plots of the ASSLB at the first cycle and the $150^{\text {th }}$ cycle. Inset shows a fitting circuit of $\mathrm{LR}(\mathrm{RC})(\mathrm{RC}) \mathrm{W}$ of the ASSLB, where the line self-inductance $(L)$, the bulk impedance of SE $(R \mathrm{~b})$, the interface impedance of SE/cathode $\left(R_{1}\right)$, the interface impedance of $\mathrm{Li} / \mathrm{SE}\left(R_{2}\right)$, the capacitor (QPE), and the $\mathrm{Li}^{+}$diffusion impedance in electrodes $\left(W_{\mathrm{s}}\right)$ were taken into account. 


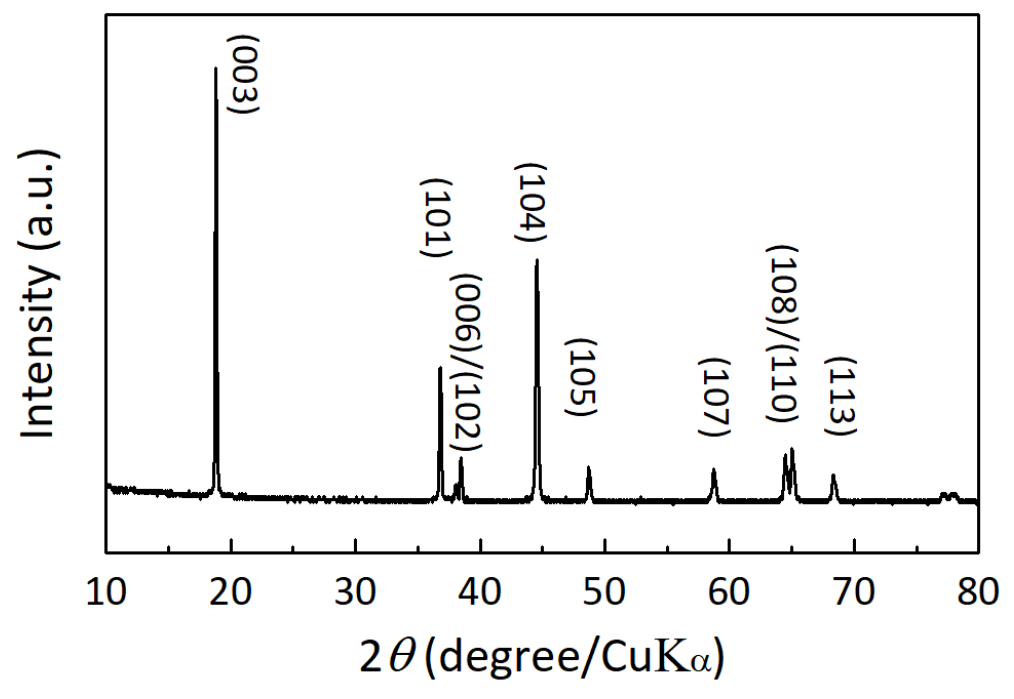

Figure S10. XRD patterns of the $\mathrm{LiNi}_{0.5} \mathrm{Co}_{0.2} \mathrm{Mn}_{0.3} \mathrm{O}_{2}$ powder. 


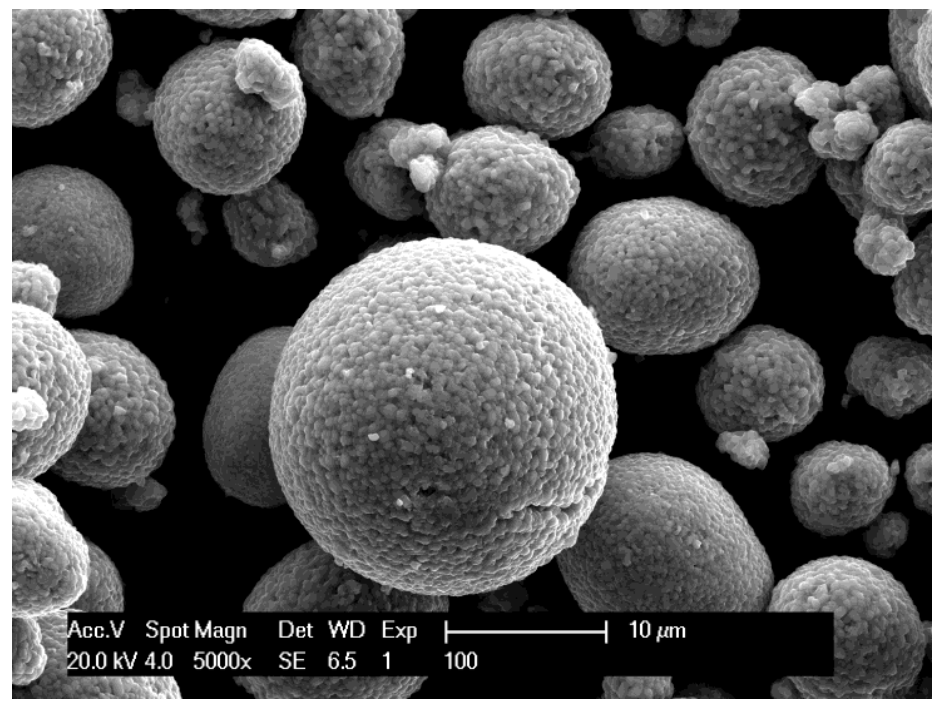

Figure S11. SEM image of the $\mathrm{LiNi} 0.5 \mathrm{Co}_{0.2} \mathrm{Mn}_{0.3} \mathrm{O}_{2}$ powder. 
Table S1. Parameters for reported sulfide SE membranes.

\begin{tabular}{|c|c|c|c|c|c|c|c|}
\hline SE & Fraction & Binder & Solvent & Thickness & $\begin{array}{l}\text { Conductivity } \\
\left(25^{\circ} \mathrm{C}\right)\end{array}$ & $\begin{array}{c}\text { Areal specific } \\
\text { resistance } \\
\left(25^{\circ} \mathrm{C}\right)\end{array}$ & References \\
\hline $0.01 \mathrm{Li}_{3} \mathrm{PO}_{4}-0.63 \mathrm{Li}_{2} \mathrm{~S}-0.36 \mathrm{SiS}_{2}$ & 96 vol. $\%$ & SBR & Toluene & l & $0.07 \mathrm{mS} \mathrm{cm}^{-1}$ & l & 1 \\
\hline $\mathrm{Li}_{3.25} \mathrm{Ge}_{0.25} \mathrm{P}_{0.75} \mathrm{~S}_{4}$ & 95 vol. $\%$ & SBR & Toluene & l & $0.035 \mathrm{mS} \mathrm{cm}{ }^{-1}$ & l & 1 \\
\hline $\mathrm{Li}_{3.25} \mathrm{Ge}_{0.25} \mathrm{P}_{0.75} \mathrm{~S}_{4}$ & 95 vol. $\%$ & Silicone rubber & N-heptane & l & $0.50 \mathrm{mS} \mathrm{cm}^{-1}$ & l & 1 \\
\hline $0.01 \mathrm{Li}_{3} \mathrm{PO}_{4}-0.63 \mathrm{Li}_{2} \mathrm{~S}-0.36 \mathrm{SiS}_{2}$ & l & Silicone rubber & N-heptane & l & $0.10 \mathrm{mS} \mathrm{cm}^{-1}$ & / & 2 \\
\hline $\mathrm{Li}_{3.25} \mathrm{Ge}_{0.25} \mathrm{P}_{0.75} \mathrm{~S}_{4}$ & 95 vol. $\%$ & Silicone rubber & N-heptane & $100 \mu \mathrm{m}$ & l & l & 3 \\
\hline $80 \mathrm{Li}_{2} \mathrm{~S}: 20 \mathrm{P}_{2} \mathrm{~S}_{5}$ & 98 vol. $\%$ & Hydrocarbon & Xylene & $200 \mu \mathrm{m}$ & l & l & 4 \\
\hline$\beta-\mathrm{Li}_{3} \mathrm{PS}_{4}$ & l & l & Toluene & $70 \mu \mathrm{m}$ & $0.20 \mathrm{mS} \mathrm{cm}^{-1}$ & $35 \Omega \mathrm{cm}^{2}$ & 5 \\
\hline$\beta-\mathrm{Li}_{3} \mathrm{PS}_{4}$ & l & l & $\mathrm{ACN}$ & $8 \mu \mathrm{m}$ & $0.12 \mathrm{mS} \mathrm{cm}^{-1}$ & $6.67 \Omega \mathrm{cm}^{2}$ & 6 \\
\hline $\mathrm{Li}_{10} \mathrm{GeP}_{2} \mathrm{~S}_{12}$ & l & l & Toluene & $90 \mu \mathrm{m}$ & $0.34 \mathrm{mS} \mathrm{cm}^{-1}$ & $26.47 \Omega \mathrm{cm}^{2}$ & 5 \\
\hline $75 \mathrm{Li}_{2} \mathrm{~S}: 25 \mathrm{P}_{2} \mathrm{~S}_{5}$ & 97 wt.\% & SBS & Anisole & $\sim 50 \mu \mathrm{m}$ & $\begin{array}{l}0.1 \mathrm{mS} \mathrm{cm}^{-1} \\
\text { at } 330 \mathrm{MPa} \\
0.2 \mathrm{mS} \mathrm{cm}^{-1} \\
\text { at } 410 \mathrm{MPa}\end{array}$ & $50-25 \Omega \mathrm{cm}^{2}$ & 7 \\
\hline
\end{tabular}




\begin{tabular}{|c|c|c|c|c|c|c|c|}
\hline $\mathrm{Li}_{6} \mathrm{PS}_{5} \mathrm{Cl}$ & 98.5 wt. $\%$ & NBR & Xylene & $30 \mu \mathrm{m}$ & $2.8 \mathrm{mS} \mathrm{cm}^{-1}$ & $1.07 \Omega \mathrm{cm}^{2}$ & 8 \\
\hline $75 \mathrm{Li}_{2} \mathrm{~S}: 25 \mathrm{P}_{2} \mathrm{~S}_{5}$ & 97 wt. \% & PPC & Anisole & $180 \mu \mathrm{m}$ & $0.11 \mathrm{mS} \mathrm{cm}-1$ & $163.6 \Omega \mathrm{cm}^{2}$ & 9 \\
\hline $\mathrm{Li}_{7} \mathrm{P}_{2} \mathrm{~S}_{8} \mathrm{I}$ & 97 wt. $\%$ & PEP-MNB & N-heptane & $70 \mu \mathrm{m}$ & $0.036 \mathrm{mS} \mathrm{cm}^{-1}$ & $194.4 \Omega \mathrm{cm}^{2}$ & 10 \\
\hline $\mathrm{Li}_{6} \mathrm{PS}_{5} \mathrm{Cl}$ & 98 wt. $\%$ & SBS-COOH & Xylene & l & $\sim 1 \mathrm{mS} \mathrm{cm}{ }^{-1}$ & l & 11 \\
\hline $\mathrm{Li}_{10} \mathrm{SnP}_{2} \mathrm{~S}_{12}$ & 97.5 wt. $\%$ & HNBR & Toluene & $\begin{array}{l}20-40 \mu \mathrm{m} \\
\text { Calendered }\end{array}$ & $3.2 \mathrm{mS} \mathrm{cm}^{-1}$ & $\begin{array}{c}0.625-1.25 \Omega \\
\mathrm{cm}^{2}\end{array}$ & 12 \\
\hline $\mathrm{Li}_{6} \mathrm{PS}_{5} \mathrm{Cl}$ & 99.85 wt. $\%$ & PTFE & None & $150 \mu \mathrm{m}$ & $2.7 \mathrm{mS} \mathrm{cm}^{-1}$ & $5.5 \Omega \mathrm{cm}^{2}$ & 13 \\
\hline $\mathrm{Li}_{6} \mathrm{PS}_{5} \mathrm{Cl}_{0.5} \mathrm{Br}_{0.5}$ & 96.4 wt. $\%$ & PI & $\mathrm{EtOH}$ & $40 \mu \mathrm{m}$ & $0.058 \mathrm{mS} \mathrm{cm}^{-1}$ & $68.9 \Omega \mathrm{cm}^{2}$ & 14 \\
\hline $\mathrm{Li}_{6} \mathrm{PS}_{5} \mathrm{Cl}$ & 99 wt. $\%$ & Acrylate-type binder & $\begin{array}{l}\text { Xylene \& } \\
\text { isobutyl isobutyrate }\end{array}$ & $30 \mu \mathrm{m}$ & $1.31 \mathrm{mS} \mathrm{cm}^{-1}$ & $2.29 \Omega \mathrm{cm}^{2}$ & 15 \\
\hline $\mathrm{Li}_{6} \mathrm{PS}_{5} \mathrm{Cl}$ & l & $\begin{array}{l}\text { Dopamine } \\
\text { hydrochloride }\end{array}$ & Chlorobenzene & $35 \mu \mathrm{m}$ & $0.2 \mathrm{mS} \mathrm{cm}^{-1}$ & $17.5 \Omega \mathrm{cm}^{2}$ & 16 \\
\hline $77.5 \mathrm{Li}_{2} \mathrm{~S}-22.5 \mathrm{P}_{2} \mathrm{~S}_{5}$ & 80 wt. $\%$ & Polyimine & / & $64 \mu \mathrm{m}$ & $0.092 \mathrm{mS} \mathrm{cm}^{-1}$ & $69.5 \Omega \mathrm{cm}^{2}$ & 17 \\
\hline $\mathrm{Li}_{5.4} \mathrm{PS}_{4.4} \mathrm{Cl}_{1.6}$ & 99.8 wt. $\%$ & PTFE & None & $30 \mu \mathrm{m}$ & $8.4 \mathrm{mS} \mathrm{cm}^{-1}$ & $0.35 \Omega \mathrm{cm}^{2} *$ & (This work) \\
\hline
\end{tabular}

* The ASR value in this work was calculated by the follow formula: $(1.49 \Omega-1.04 \Omega)^{*} 0.785 \mathrm{~cm}^{2}=0.35 \Omega \mathrm{cm}^{2}$. The impedance value for ASR calculation is obtained by the tested impedance value subtracting the resistance contribution (1.04 $\Omega$, Figure $\mathrm{S} 4 \mathrm{~b})$ from testing wires, electrical contact, etc. 


\section{References}

(1) Inada, T.; Takada, K.; Kajiyama, A.; Kouguchi, M.; Sasaki, H.; Kondo, S.; Watanabe, M.; Murayama, M.; Kanno, R. Fabrications and properties of composite solid-state electrolytes. Solid State Ionics 2003, 158 (3-4), 275-280.

(2) Inada, T.; Takada, K.; Kajiyama, A.; Sasaki, H.; Kondo, S.; Watanabe, M.; Murayama, M.; Kanno, R. Silicone as a binder in composite electrolytes. J. Power Sources 2003, $119(6), 948-950$.

(3) Inada, T.; Kobayashi, T.; Sonoyama, N.; Yamada, A.; Kondo, S.; Nagao, M.; Kanno, R. All solid-state sheet battery using lithium inorganic solid electrolyte, thio-LISICON. J. Power Sources 2009, 194 (2), 1085-1088.

(4) Fujiki, S.; Yamada, T.; Aihara, Y.; Park, Y.; Kim, T. Y.; Baek, S. W.; Lee, J. M.; Doo, S.; Machida], N. A rocking chair type all-solid-state lithium ion battery adopting $\mathrm{Li}_{2} \mathrm{O}-$ $\mathrm{ZrO}_{2}$ coated $\mathrm{LiNi}_{0 .} \mathrm{Co}_{0.15} \mathrm{Al}_{0.05} \mathrm{O}_{2}$ and a sulfide based electrolyte. J. Power Sources 2014, 248(15):943-950.

(5) Nam, Y. J.; Cho, S. J.; Oh, D. Y.; Lim, J. M.; Kim, S. Y.; Song, J. H.; Lee, Y. G.; Lee, S. Y.; Jung, Y. S. Bendable and Thin Sulfide Solid Electrolyte Film: A New Electrolyte Opportunity for Free-Standing and Stackable High-Energy All-Solid-State Lithium-Ion Batteries. Nano Lett. 2015, 15 (5), 3317.

(6) Wang, H.; Hood, Z. D.; Xia, Y.; Liang, C. Fabrication of ultrathin solid electrolyte membranes of $\beta$-Lii $\mathrm{PS}_{4}$ nanoflakes by evaporation-induced self-assembly for all-solidstate batteries. J. Mater. Chem. A 2016, 4 (21), 8091-8096.

(7) Sakuda, A.; Kuratani, K.; Yamamoto, M.; Takahashi, M.; Takeuchi, T.; Kobayashi, H. All-Solid-State Battery Electrode Sheets Prepared by a Slurry Coating Process. $J$. Electrochem. Soc. 2017, 164 (12), A2474-A2478.

(8) Nam, Y. J.; Oh, D. Y.; Jung, S. H.; Jung, Y. S. Toward practical all-solid-state lithium-ion batteries with high energy density and safety: Comparative study for electrodes fabricated by dry- and slurry-mixing processes. J. Power Sources 2018, 375, 93-101.

(9) Yamamoto, M.; Terauchi, Y.; Sakuda, A.; Takahashi, M. Binder-free sheet-type all- 
solid-state batteries with enhanced rate capabilities and high energy densities. Sci. Rep. 2018, $8(1), 1212$.

(10) Choi, S. J.; Lee, S. H.; Ha, Y. C.; Yu, J. H.; Doh, C. H.; Lee, Y.; Park, J. W.; Lee, S. M.; Shin, H. C. Synthesis and electrochemical characterization of a glass-ceramic $\mathrm{Li}_{7} \mathrm{P}_{2} \mathrm{~S}_{8} \mathrm{I}$ solid electrolyte for all-solid-state Li-ion batteries. J. Electrochem. Soc. 2018, 165 (5), A952-A962.

(11) Lee, K.; Lee, J.; Choi, S.; Char, K.; Choi, J. W. Thiol-Ene Click Reaction for Fine Polarity Tuning of Polymeric Binders in Solution-Processed All-Solid-State Batteries. ACS Energy Lett. 2019, 4(1):94-101.

(12) Riphaus, N.; Strobl, P.; Stiaszny, B.; Zinkevich, T.; Yavuz, M.; Schnell, J.; Indris, S.; Gasteiger, H. A.; Sedlmaier, S. J. Slurry-Based Processing of Solid Electrolytes: A Comparative Binder Study. J. Electrochem. Soc. 2018, 165 (16), A3993-A3999.

(13) Hippauf, F.; Schumm, B.; Doerfler, S.; Althues, H.; Fujiki, S.; Shiratsuchi, T.; Tsujimura, T.; Aihara, Y.; Kaskel, S. Overcoming binder limitations of sheet-type solidstate cathodes using a solvent-free dry-film approach. Energy Storage Mater. 2019, 21, 390-398.

(14) Kim, D. H.; Lee, Y.-H.; Song, Y. B.; Kwak, H.; Lee, S.-Y.; Jung, Y. S. Thin and Flexible Solid Electrolyte Membranes with Ultrahigh Thermal Stability Derived from Solution-Processable Li Argyrodites for All-Solid-State Li-Ion Batteries. ACS Energy Lett. 2020, 5 (3), 718-727.

(15) Lee, Y. G.; Fujiki, S.; Jung, C.; Suzuki, N.; Yashiro, N.; Omoda, R.; Ko, D. S.; Shiratsuchi, T.; Sugimoto, T.; Ryu, S. High-energy long-cycling all-solid-state lithium metal batteries enabled by silver-carbon composite anodes. Nat. Energy 2020, 5 (4), 299-308.

(16) Liu, G.; Shi, J.; Zhu, M.; Weng, W.; Shen, L.; Yang, J.; Yao, X. Ultra-thin freestanding sulfide solid electrolyte film for cell-level high energy density all-solid-state lithium batteries. Energy Storage Mater. 2021, 38, 249-254.

(17) Whiteley, J. M.; Taynton, P.; Zhang, W.; Lee, S.-H. Ultra-thin Solid-State Li-Ion Electrolyte Membrane Facilitated by a Self-Healing Polymer Matrix. Adv. Mater. 2015, 
27 (43), 6922-6927. 